Check for updates

Cite this: RSC Adv., 2021, 11, 20252

\title{
Dynamic ionic radius of alkali metal ions in aqueous solution: a pulsed-field gradient NMR study $\dagger$
}

\author{
Kikuko Hayamizu, (D) *a Yusuke Chiba (D) ${ }^{\mathrm{b}}$ and Tomoyuki Haishic
}

The dynamic behavior of alkali metal ions, $\mathrm{Li}^{+}, \mathrm{Na}^{+}, \mathrm{K}^{+}, \mathrm{Rb}^{+}$and $\mathrm{Cs}^{+}$in aqueous solutions is one of the most important topics in solution chemistry. Since these alkali metals contain nuclear magnetic resonance (NMR) active nuclei, it is possible to directly measure the diffusion constants of the alkali metal ions using the pulsed field gradient (PFG) NMR method. In this paper, the ${ }^{7} \mathrm{Li},{ }^{23} \mathrm{Na},{ }^{87} \mathrm{Rb},{ }^{133} \mathrm{Cs}$ and ${ }^{1} \mathrm{H}$ resonances are observed for diffusion constants in aqueous solution and the solvent $\mathrm{H}_{2} \mathrm{O}$. Until now, the values of the diffusion constant have been lacking when discussing hydration effects around alkali metal ions. It is known that the static ionic radius $\left(R_{\text {ion }}\right)$ increases with increasing the atomic number, and the experimental diffusion constants also increase with increasing the atomic number, which is opposite to the Stokes-Einstein (SE) relation. It suggests that alkali metal ions diffuse through a space of $10^{-6} \mathrm{~m}$ accompanying the hydrated spheres with a time interval of $10^{-3} \mathrm{~s}$. For each alkali metal ion, the dynamic ionic radius is evaluated.

Received 23rd March 2021 Accepted 19th May 2021

DOI: 10.1039/d1ra02301b

rsc.li/rsc-advances

\section{Introduction}

The behavior of alkaline salts in aqueous solutions is an important topic in solution chemistry. Hydrated ions in aqueous solutions have been the subject of numerous studies and fundamental studies have been reviewed., ${ }^{1,2}$ Various techniques have been continuously used for studies on the hydration of the alkali metal ions, for example, in recent papers, neutron diffraction, ${ }^{3}$ large-angle X-ray scattering and doublereference infrared (IR) spectroscopy, ${ }^{4}$ oxygen K-edge X-ray absorption spectroscopy, ${ }^{5}$ and theoretical approaches. ${ }^{6-8}$ Most studies are concerned with the short-range effects of the hydration of alkali metal ions. Because these alkali metals include nuclear magnetic resonance (NMR) active nuclei, the diffusion constants could be measured directly using the pulsed-field gradient (PFG) NMR method. In this paper, the ${ }^{7} \mathrm{Li}$, ${ }^{23} \mathrm{Na},{ }^{87} \mathrm{Rb},{ }^{133} \mathrm{Cs}$ and ${ }^{1} \mathrm{H}$ resonances were observed for the diffusion constants of the alkali metal ions and the solvent $\mathrm{H}_{2} \mathrm{O}$. The diffusion measurements were performed in a time scale of $10^{-3} \mathrm{~s}$ and were very long compared with the X-ray, IR, and

${ }^{a}$ Institute of Applied Physics, Tsukuba University, Tennodai, Tsukuba 305-8573, Japan. E-mail: hayamizu.k3@gmail.com

${ }^{b}$ Graduate School of Pure and Applied Sciences and Tsukuba Research Center for Energy, Materials Science (TREMS), University of Tsukuba, Tennodai, Tsukuba 3058573, Japan

'MRTechnology, TCI-B5, Sengen, Tsukuba 305-0047, Japan

$\dagger$ Electronic supplementary information (ESI) available: The Hahn and stimulated echo pulse sequences for the PFG NMR. Measuring conditions of the Hahn-PFG ${ }^{1} \mathrm{H},{ }^{7} \mathrm{Li},{ }^{23} \mathrm{Na},{ }^{133} \mathrm{Ce}$ and those of STE-PFG for ${ }^{87} \mathrm{Rb}$ with short relaxation times. The Stokes-Einstein plot ( $D$ versus $k T / \pi \eta$ ) of pure $\mathrm{H}_{2} \mathrm{O}$, and the rations of $D_{\mathrm{Li}}$ and $D_{\mathrm{Na}}$ with each solvent $D_{\mathrm{H}_{2} \mathrm{O}}$. See DOI: $10.1039 / \mathrm{d} 1 \mathrm{ra} 02301 \mathrm{~b}$ neutron diffraction spectroscopy, and belong to macroscopic properties such as viscosity and ionic conductivity. The PFGNMR method measures positional migration over a space of $10^{-6} \mathrm{~m}$. Although measurements of viscosity and ionic conductivity have been widely conducted, experimental values of diffusion constants are limited.

The relationship between the diffusion constant $D$ and the viscosity $(\eta)$ is known as the Stokes-Einstein (SE) equation:

$$
D=\frac{1}{c r_{\mathrm{s}}} \frac{k T}{\pi \eta}
$$

where $k$ is the Boltzmann constant, $r_{\mathrm{s}}$ is the Stokes radius of the diffusing species, and $c$ is the constant, for which the theoretical ranges are between 4 and 6 for slip and stick boundary conditions, respectively. ${ }^{9}$

The PFG-NMR method can afford directly the diffusion constants of NMR active nuclei. As $D$ is related to the ionic conductivity via the Nernst-Einstein relation, the experimental $D$ values of Li solution electrolytes for Li-ion batteries (LIB) have been piled up for $\mathrm{Li}^{+}\left({ }^{7} \mathrm{Li}\right)$ and anions $\left({ }^{19} \mathrm{~F},{ }^{11} \mathrm{~B}\right.$, and others) in organic solvents. ${ }^{10}$

Ionic liquids are another class of solution electrolyte and we have reported temperature-dependent physical constants such as density, ionic conductivity, $\eta$, and $D$ for various ionic liquids and Li salt-doped ionic liquids. $D$ is macroscopic in nature, and each electrolyte component has a different value, which can be measured independently for an individual nucleus. Experimental values of $D$ relate well with the experimental $\eta$ by the SE relation. The plots of $D$ versus $k T / \pi \eta$ are always linear and the gradients afford the experimental values of $1 / c r_{s}$. Discussion on the constant $c$ and the Stokes radius $r_{\mathrm{s}}$ is necessary for practical 
systems. Reasonable $r_{\mathrm{s}}$ values may be calculated by molecular orbital methods, and the $c$ values were evaluated experimentally in ionic liquid systems. We have reported the experimental $c$ values in the $\mathrm{SE}$ relation for the cations, anions and solvated $\mathrm{Li}^{+}$ in ionic liquids composed of cations, 1-ethyl-3methylimidazolium (EMIm) and $N$-methyl- $N$-propylpyrrolidinium $\left(\mathrm{P}_{13}\right){ }^{1 \mathbf{1 1 2}}$ The anions were bis(trifluoromethanesulfonyl)amide (TFSA) and bis(fluorosulfonyl) amide (FSA) and the systems were prepared without and with doping of a Li salt. Using the temperature-dependent values of $D$ and $\eta$, the plots of $D$ versus $k / \pi \eta$ were always linear. From the gradient of $1 / c r_{\mathrm{s}}$, experimental value of $c r_{\mathrm{s}}$ was evaluated for each component. The $c$ value was estimated assuming that the $r_{\mathrm{s}}$ value is the van del Waals radius of the molecular orbital calculation. The approximate $c$ values were 2.4 to 3.1 for cations (EMIm and $\mathrm{P}_{13}$ ), 2.7 to 3.7 for anions (TFSA and FSA), and 3.5 to 4.5 for the $\mathrm{Li}^{+}$solvated by anions. In the ionic liquid systems, the $c$ values of the cation are smaller than those of the anion. It indicates that the experimental measurable values $D$ and $\eta$ are well explained by the SE relation, and the $c r_{\mathrm{s}}$ value is a constant in each system. It is important to note that $c$ is not a universal constant.

In recent years, alkali metals and alkaline earth metals such as $\mathrm{Na}^{+}, \mathrm{K}^{+}, \mathrm{Mg}^{2+}$, and $\mathrm{Ca}^{2+}$ have been targeted for nextgeneration energy storage systems from the viewpoint of resource conservation. To date, organic solvents have been widely used in LIBs. The possibility of using aqueous solutions is being explored for the prevention of volatility, in addition of the usages of polymer and solid electrolytes. Similarly, fuel cell technology is important in its contribution to power sources. In 1988, diffusion coefficients of $\mathrm{Li}^{+}, \mathrm{Na}^{+}$, and $\mathrm{Cs}^{+}$were observed using steady-state field gradient spin-echo NMR method in aqueous solutions. ${ }^{13}$ Recently, ${ }^{1} \mathrm{H}^{+},{ }^{7} \mathrm{Li}^{+},{ }^{23} \mathrm{Na}^{+}$and ${ }^{133} \mathrm{Cs}^{+}$ diffusion constants were measured in cation-exchange membranes by the PFG-NMR method. ${ }^{14}$ Furthermore, $\mathrm{Na}^{+}$and $\mathrm{K}^{+}$ions are important in biological systems. In humans, $\mathrm{Na}^{+}$is present outside the cells and $\mathrm{K}^{+}$inside the cells. In particular, $\mathrm{Na}^{+}$circulates mainly in the form of blood, and its concentration is maintained by the kidneys. $\mathrm{Na}^{+}$is the main factor in the formation of osmotic pressure to retain water.

We observed the diffusion constants of ${ }^{7} \mathrm{Li}^{+},{ }^{23} \mathrm{Na}^{+},{ }^{87} \mathrm{Rb}^{+}$and ${ }^{133} \mathrm{Cs}^{+}$in aqueous solutions. Using the reported values of $D$ and $\eta$ of pure $\mathrm{H}_{2} \mathrm{O}$, the $c$ value was estimated to be 4.8 . From the experimental diffusion constants of alkali metal ions and solvent $\mathrm{H}_{2} \mathrm{O}$, the dynamic radius of each alkali metal ion is proposed. The large hydration ability of $\mathrm{Li}$ and $\mathrm{Na}$ ions is discussed.

\section{Experimental}

The PFG NMR measurements were performed at $303 \mathrm{~K}$ by using a Tecmag Apollo and an NT-NMR console (Houston, TX) equipped with a JEOL PFG-probe with a well-shaped rectangular PFG of the maximum strength is $24 \mathrm{Tm}^{-1}$ (Tokyo). The basic properties of each nuclei are summarized in Table 1 , where the $T_{1}$ and $T_{2}$ values of the alkali metal ions were obtained in the diluted aqueous solutions at $303 \mathrm{~K}$ in this study. The $T_{1}$ and $T_{2}$
Table 1 Basic properties and $T_{1}$ and $T_{2}$ at $303 \mathrm{~K}$ for the nuclei of alkali metal ions

\begin{tabular}{llllll}
\hline Nucleus & $T_{1}$ & $T_{2}$ & $\begin{array}{l}\text { Frequency } \\
(\mathrm{MHz})\end{array}$ & $\mathrm{I}$ & $Q^{b}\left(10^{-31} \mathrm{~m}^{2}\right)$ \\
\hline${ }^{7} \mathrm{Li}$ & $25 \mathrm{~s}$ & $5 \mathrm{~s}$ & 78.45 & $3 / 2$ & -40.1 \\
${ }^{23} \mathrm{Na}$ & $46 \mathrm{~ms}$ & $23 \mathrm{~ms}$ & 53.39 & $3 / 2$ & 104 \\
${ }^{39} \mathrm{~K}$ & $64 \mathrm{~ms}$ & $32 \mathrm{~ms}$ & $18.68^{a}$ & $3 / 2$ & 58.5 \\
${ }^{87} \mathrm{Rb}$ & $1.8 \mathrm{~ms}$ & $1.2 \mathrm{~ms}$ & 27.85 & $3 / 2$ & 133.5 \\
${ }^{133} \mathrm{Cs}$ & $9 \mathrm{~s}$ & $1.2 \mathrm{~s}$ & 26.47 & $7 / 2$ & -3.43 \\
${ }^{1} \mathrm{H}\left(\mathrm{H}_{2} \mathrm{O}\right)$ & $3.5 \mathrm{~s}$ & - & 201.85 & $1 / 2$ & -
\end{tabular}

${ }^{a}$ Observed by a JEOL ECZ-400 spectrometer at the field strength of 9.404 T. ${ }^{b}$ Nuclear quadrupole moment from Bruker NMR properties of selected isotopes.

values are important to determine the diffusion measuring conditions. The PFG NMR pulse sequences are shown for the Hahn echo pulse sequence $\left({ }^{1} \mathrm{H},{ }^{7} \mathrm{Li},{ }^{23} \mathrm{Na}\right.$, and $\left.{ }^{133} \mathrm{Ce}\right)$ and the stimulated echo pulse sequence $\left({ }^{87} \mathrm{Rb}\right)$ in Fig. $\mathrm{S} 1$ in ESI. $\dagger$ The $T_{1}$ and $T_{2}$ values at $303 \mathrm{~K}$ are sufficiently long for ${ }^{1} \mathrm{H},{ }^{7} \mathrm{Li},{ }^{23} \mathrm{Na}$, and ${ }^{133} \mathrm{Cs}$ to use the Hahn-echo PFG NMR pulse sequence and the measurements were performed with the PFG strength 1.26 $\mathrm{Tm}^{-1}$. The precise measurement details are described in the ESI. $\dagger$ Because the $T_{1}$ and $T_{2}$ values of ${ }^{87} \mathrm{Rb}^{+}$were extremely short, the stimulated echo PFG pulse sequence was used with the $g$ value of $10.0 \mathrm{Tm}^{-1}$ (Fig. S2, ESI $\dagger$ ). ${ }^{39} \mathrm{~K}$ belongs to a low- $\gamma$ nuclei and a JEOL ECZ-400 spectrometer can measure the ${ }^{39} \mathrm{~K}$ spectra at 18.6 MHz. The $T_{1}$ and $T_{2}$ values for ${ }^{39} \mathrm{~K}$ were short (Table 1). Unfortunately, the maximum PFG strength equipped was $0.3 \mathrm{Tm}^{-1}$. Several attempts were made to obtain the ${ }^{39} \mathrm{~K}$ diffusion constant for the saturated aqueous solution ( $3 \mathrm{M}$ ), but a reliable $D$ value for $\mathrm{K}^{+}$could not be obtained because of poor decay of the echo attenuation. The repetition time of every experiment including relaxation time measurement was set at least five times longer than $T_{1}$

The aqueous sample was placed in a $5 \mathrm{~mm}$ NMR microtube (BMS-005J, Shigemi, Tokyo) to a height of $5 \mathrm{~mm}$. The aqueous $\mathrm{LiCl}$ and $\mathrm{NaCl}$ samples were prepared by diluting concentrated samples.

\section{Results and discussion}

\section{Concentration dependences of diffusion constants for $\mathrm{Li}^{+}, \mathrm{Na}^{+}$ and solvent $\mathrm{H}_{2} \mathrm{O}$}

The salt concentration dependences of the diffusion constants for ${ }^{7} \mathrm{Li}\left(D_{\mathrm{Li}}\right),{ }^{23} \mathrm{Na}\left(D_{\mathrm{Na}}\right)$, and ${ }^{1} \mathrm{H}$ solvent $\mathrm{H}_{2} \mathrm{O}\left(D_{\mathrm{H}_{2} \mathrm{O}-\mathrm{Li}}\right.$ and $D_{\mathrm{H}_{2} \mathrm{O}-}$ $\mathrm{Na})$ are shown in Fig. 1. In homogenous solutions, a unique diffusion constant $(D)$ can be determined independently of measurement conditions such as the diffusion time $(\Delta)$. In diluted regions $(\leq 2 \mathrm{M})$, each diffusion constant was a single component without dependence of $\Delta\left(10^{-3} \mathrm{~s}\right.$ order $)$. The obtained $D$ values are physical constants because of independence of the measuring parameters of PFG-NMR. In general, for heterogeneous materials such as zeolites and solid electrolytes, the apparent diffusion constant may depend on $\Delta$ and $g$, in which case the diffusion constant as a physical constant cannot 


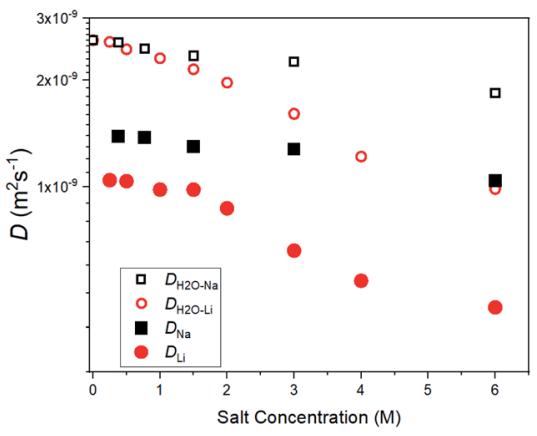

Fig. 1 Concentration-dependent diffusion constants for ${ }^{7} \mathrm{Li}\left(D_{\mathrm{Li}}\right),{ }^{23} \mathrm{Na}$ $\left(D_{\mathrm{Na}}\right.$ ), and ${ }^{1} \mathrm{H}$ (solvent $\mathrm{H}_{2} \mathrm{O}, D_{\mathrm{H}_{2} \mathrm{O}-\mathrm{Li}}$ and $D_{\mathrm{H}_{2} \mathrm{O}-\mathrm{Na}}$ ) at $303 \mathrm{~K}$ in aqueous solutions.

be obtained. In very concentrated regions $(\geq 4 \mathrm{M})$, a small amount of a slower component coexists in $D_{\mathrm{H}_{2} \mathrm{O}}, D_{\mathrm{Li}}$ and $D_{\mathrm{Na}}$, and strictly speaking, they are not homogeneous systems; this requires further study.

The $D_{\mathrm{Li}}$ values were smaller than the $D_{\mathrm{Na}}$ values over the whole concentration range. A larger concentration dependence was observed for $D_{\mathrm{Li}}$ than for $D_{\mathrm{Na}}$. Solvent $\mathrm{H}_{2} \mathrm{O}$ diffusion constants decreased slightly with an increase in concentration and the concentration dependence of $D_{\mathrm{H}_{2} \mathrm{O}-\mathrm{Li}}$ was larger than that of $D_{\mathrm{H}_{2} \mathrm{O}-\mathrm{Na}}$, correlating with the relations of the $D_{\mathrm{Li}}$ and $D_{\mathrm{Na}}$. The ratios of $D_{\mathrm{H}_{2} \mathrm{O}-\mathrm{Li}} / D_{\mathrm{Li}}$ and $D_{\mathrm{H}_{2} \mathrm{O}-\mathrm{Na}} / D_{\mathrm{Na}}$ were plotted against the salt concentration in Fig. $\mathrm{S} 4$ in the ESI $\dagger$ and they were almost constant for the concentration and $D_{\mathrm{H}_{2} \mathrm{O}-\mathrm{Li}} / D_{\mathrm{Li}}>D_{\mathrm{H}_{2} \mathrm{O}-\mathrm{Na}} /$ $D_{\mathrm{Na}}$. The temperature-dependent diffusion constants of pure $\mathrm{H}_{2} \mathrm{O}$ have been reported ${ }^{15}$ and the value of $2.6 \times 10^{-9} \mathrm{~m}^{2} \mathrm{~s}^{-1}$ at $303 \mathrm{~K}$ is consistent with the present value for $\mathrm{H}_{2} \mathrm{O}$ without including salt.

We have reported the salt concentration dependences of the diffusion constants of $\mathrm{Li}^{+}$ions for $\mathrm{LiBF}_{4}$ and $\mathrm{LiN}\left(\mathrm{SO}_{2} \mathrm{CF}_{3}\right)_{2}$ in two organic solvents, propylene carbonate (PC) and $\gamma$-butyrolactone (GBL). Near the infinitesimal concentration region, clear concentration dependences of the diffusion constants of Li ions and anions were observed. ${ }^{16}$ In the aqueous solutions, the concentration dependence of $D_{\mathrm{Li}}$ is small compared with those in organic solvents.

In liquid crystal systems, the SE equation (eqn (1)) holds well between experimental $D$ and $\eta$ as indicated. ${ }^{11,12}$ In many cases, the constant $c$ has been treated as 6 , but it varies widely for each species in ionic liquids. In this study, we tried to find the $c$ value for $\mathrm{H}_{2} \mathrm{O}$. In the ESI, $\uparrow$ using published data of the temperaturedependent $D_{\mathrm{H}_{2} \mathrm{O}}$ and $\eta$ of $\mathrm{H}_{2} \mathrm{O}$, the plot of the SE relation ( $D$ versus $1 / \pi \eta$ ) is linear with the gradient $1 / c r_{\mathrm{s}}$. The experimental value of $c r_{\mathrm{s}}$ is $673 \mathrm{pm}$. When the ionic radius $R_{\text {ion }}$ of $\mathrm{H}_{3} \mathrm{O}^{+}(141$ $\mathrm{pm}$ ) is assumed to be $r_{\mathrm{s}}$, the $c$ value is 4.8 for $\mathrm{H}_{2} \mathrm{O}$. Following the classical relation, $c$ value is either 4 nor 6 , then the $r_{\mathrm{s}}$ values are 168 or $112 \mathrm{pm}$ for 4 or 6 , respectively. The estimate of $c=4.8$ of $\mathrm{H}_{2} \mathrm{O}$ is tentative, but we will use this value in our discussion. The viscosity of the solution at each salt concentration was estimated by eqn (2).

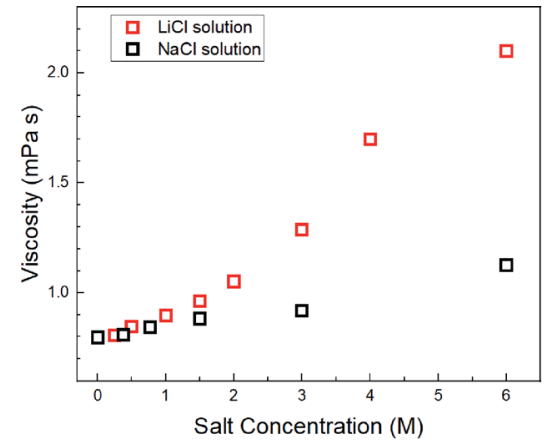

Fig. 2 Estimated viscosity for the aqueous $\mathrm{LiCl}$ and $\mathrm{NaCl}$ solutions at $303 \mathrm{~K}$.

$$
\eta_{\text {solution }}=\frac{1}{c_{\mathrm{H}_{2} \mathrm{O}} r_{\mathrm{H}_{3} \mathrm{O}}} \frac{k T}{\pi D_{\mathrm{H}_{2} \mathrm{O}}}
$$

Assuming $c=4.8$ and $r_{\mathrm{H}_{3} \mathrm{O}}=141 \mathrm{pm}$, the concentrationdependent viscosity was estimated from the $D_{\mathrm{H}_{2} \mathrm{O}}$ for the aqueous $\mathrm{LiCl}$ and $\mathrm{NaCl}$ solutions (Fig. 2).

The increase in viscosity with the concentration increase in aqueous $\mathrm{LiCl}$ solutions was larger than that in the aqueous $\mathrm{NaCl}$ solutions, which were calculated by $D_{\mathrm{H}_{2} \mathrm{O}-\mathrm{Na}}$ and $D_{\mathrm{H}_{2} \mathrm{O}-\mathrm{Li}}$ (Fig. 1).

The dynamic Stokes radius for the alkali metal ions ( $\mathrm{Li}$ and $\mathrm{Na}$ ) is estimated at each concentration of aqueous solution with $c=4.8$ :

$$
r_{\mathrm{s}}(\text { alkali })=\frac{k T}{4.8 \times \pi \eta} \frac{1}{D_{\text {alkali }}}
$$

The estimated values are plotted versus the salt concentration for the $\mathrm{LiCl}$ and $\mathrm{NaCl}$ solutions in Fig. 3.

It is not surprising that Fig. 3 is similar to Fig. S4, $\dagger$ but Fig. 3 has a clearer meaning of the $Y$-axis. The estimated $r_{\mathrm{s}}\left(\mathrm{Li}^{+}\right)$values scattered slightly without an explicit trend versus the salt concentration. The $r_{\mathrm{s}}\left(\mathrm{Na}^{+}\right)$values were almost independent of salt concentration. In this stage, the ion association effects must be considered. It is known that ion association increases with increase in the salt concentration measured in the ionic

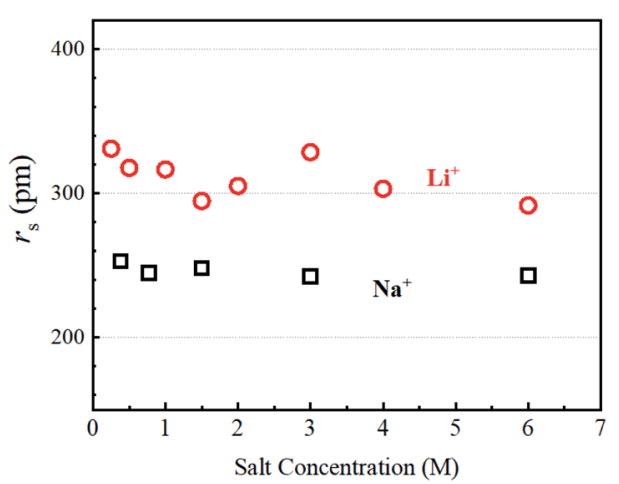

Fig. 3 Estimated Stokes radius, $r_{\mathrm{s}}$ of $\mathrm{Li}^{+}$and $\mathrm{Na}^{+}$ions versus the salt concentration. 
conductivity. We reported the ion association effects in organic $\mathrm{Li}^{+}$solutions, where the solvation around $\mathrm{Li}^{+}$is insensitive to the ion association. ${ }^{17}$ Because of the strong solvation ability of the organic solvent with high dielectric constant such as PC and GBL, the solvated $\mathrm{Li}^{+}$ions associate with anions for ion pairing. Organic anions are weakly solvated in organic solution electrolytes. The ion association in organic solvents takes place between solvated $\mathrm{Li}^{+}$and solvated anions. ${ }^{16}$ In aqueous solutions, the ion association effects on the hydration can be assumed to be negligible in diluted regions. The $r_{\mathrm{s}}(\mathrm{Li})$ and $r_{\mathrm{s}}(\mathrm{Na})$ values suggest that the dynamic diffusion constants include the $\mathrm{H}_{2} \mathrm{O}$ solvation effects. The hydration around $\mathrm{Li}^{+}$is larger than that around $\mathrm{Na}^{+}$and the hydration effect is insensitive to salt concentration at $303 \mathrm{~K}$.

It is noted that in aqueous solutions, ${ }^{7} \mathrm{Li} T_{1}$ values varied from 25 to $8 \mathrm{~s}$ with the increase in salt concentration and they were very longer than the ${ }^{7} \mathrm{Li} T_{1}$ values in organic solvents (under $3 \mathrm{~s}$ ) and in ionic liquids $(\sim 0.3 \mathrm{~s}) .{ }^{\mathbf{1 1} 12}$ The relaxation mechanism of ${ }^{7} \mathrm{Li} T_{1}$ is mainly quadrupole interaction, and in the extreme narrowing condition, $1 / T_{1}\left({ }^{7} \mathrm{Li}\right)$ is proportional to quadrupole coupling constant $\left(e^{2} q Q / h\right)^{2}$, where $q$ is the electric field gradient around ${ }^{7} \mathrm{Li}$ nuclei and deeply related to the shape of circumstance of ${ }^{7} \mathrm{Li}$ nuclei. The better cubic shape around the $\mathrm{Li}^{+}$ion reduces $q$, and $T_{1}\left({ }^{7} \mathrm{Li}\right)$ value becomes longer because of the smaller quadrupole effect. The longer ${ }^{7} \mathrm{Li} T_{1}$ values in the diluted aqueous solutions suggest a good cubic symmetry of ${ }^{7} \mathrm{Li}$. The ${ }^{23} \mathrm{Na} T_{1}$ values were shorter owing to the larger nuclear quadrupole moment (Table 1) and varied from 64 to $46 \mathrm{~ms}$ with the increase in salt concentration. ${ }^{1} \mathrm{H} T_{1}\left(\mathrm{H}_{2} \mathrm{O}\right)$ varied from 3.6 to $2.1 \mathrm{~s}$ (Li solution) and from 3.6 to $3.1 \mathrm{~s} \mathrm{(Na} \mathrm{solution.)} \mathrm{with} \mathrm{the}$ increase in salt concentration. The larger degree of the decrease in ${ }^{7} \mathrm{Li} T_{1}$ and $\mathrm{H}_{2} \mathrm{O} T_{1}$ suggests stronger interactions in $\mathrm{Li}-\mathrm{H}_{2} \mathrm{O}$ compared with that in $\mathrm{Na}-\mathrm{H}_{2} \mathrm{O}$ in aqueous solutions. The decrease of ${ }^{7} \mathrm{Li} T_{1}$ with the increase of the salt concentration suggests decreasing the cubic symmetry of the solvation structure around $\mathrm{Li}^{+}$and $\mathrm{Na}^{+}$.

\section{Diffusion constants of alkali metal ions and solvent $\mathrm{H}_{2} \mathrm{O}$}

In diluted regions, the values of $D_{\mathrm{Li}}, D_{\mathrm{Na}}$ and $D_{\mathrm{H} 2 \mathrm{O}}$ are shown to be insensitive to the salt concentration and the data about $1 \mathrm{M}$

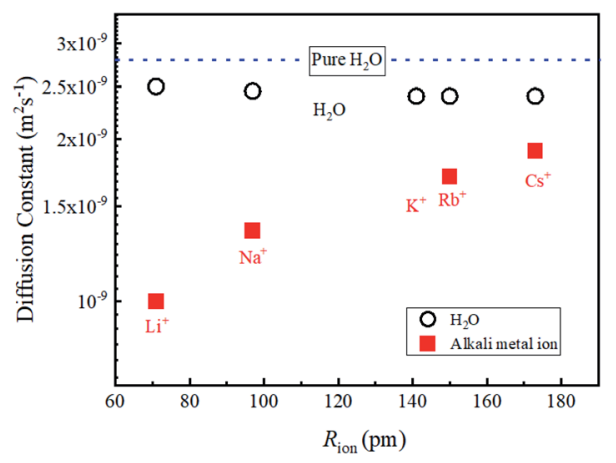

Fig. 4 Diffusion constants of alkali metal ions about $1 \mathrm{M}$ in aqueous solution at $303 \mathrm{~K}$ versus the ionic radius $R_{\text {ion. }}$. The $D_{\mathrm{H}_{2} \mathrm{O}}$ values (including diluted $\mathrm{KCl}$ solution) are shown and the $D_{\mathrm{H}_{2} \mathrm{O}}$ value of pure $\mathrm{H}_{2} \mathrm{O}$ is slightly faster than those of the solvent $\mathrm{H}_{2} \mathrm{O}$. are used to compare the data of other alkali metal ions of $\mathrm{Rb}^{+}$ and $\mathrm{Cs}^{+}$. The salts used in this study were $\mathrm{Rb}_{2} \mathrm{CO}_{3}$ and $\mathrm{Cs}_{2} \mathrm{CO}_{3}$. The concentration of aqueous solutions was about $1 \mathrm{M}$. It was confirmed that with dilution, the $D_{\mathrm{Rb}} D_{\mathrm{Cs}}$ and $D_{\mathrm{H} 2 \mathrm{O}}$ values did not vary within experimental error. Attempts to obtain the ${ }^{39} \mathrm{~K}$ diffusion constants were made using a JEOL ECZ-400 spectrometer under small PFG strength $\left(0.3 \mathrm{Tm}^{-1}\right)$. Unfortunately, a reliable value of the $D_{\mathrm{K}}$ was not observed. The data of ${ }^{39} \mathrm{~K} T_{1}$ and $T_{2}$ obtained under the field strength of 9.404 $\mathrm{T}\left({ }^{1} \mathrm{H}\right.$ frequency $400.39 \mathrm{MHz}$ ) are relatively short (Table 1).

The diffusion constants of alkali metal ions and solvent $\mathrm{H}_{2} \mathrm{O}$ about $1 \mathrm{M}$ including a diluted $\mathrm{KCl}$ solution at $303 \mathrm{~K}$ are plotted versus the reported ionic radius $\left(R_{\text {ion }}\right)^{2}$ in Fig. 4 .

The $D_{\mathrm{Li}}$ is the slowest and increases for $\mathrm{Na}^{+}, \mathrm{Rb}^{+}$, and $\mathrm{Cs}^{+}$ (Fig. 4), and the ionic radius of $\mathrm{Li}\left(R_{\mathrm{ion}}(\mathrm{Li})\right)$ is smallest of the alkali metal ions. Faster $D$ is observed for alkaline metal ion with larger $R_{\text {ion. }}$. This trend is opposite to that of $D$ which is proportional to $1 / R_{\text {ion }}$

The diffusion constants of solvent $\mathrm{H}_{2} \mathrm{O}$ are slightly slower than the $D$ value of pure $\mathrm{H}_{2} \mathrm{O}$. This suggests that the viscosity of the alkali ion aqueous solutions changes little in diluted regions. To obtain the Stokes radius $\left(r_{\mathrm{s}}\right)$ (i.e., dynamic ionic radius), the viscosity of each solution was calculated (eqn (2)) and then the $r_{\mathrm{s}}$ was evaluated (eqn (3)). Here we assume that the constant $c=4.8$ is the same as that of pure $\mathrm{H}_{2} \mathrm{O}$. To estimate dynamic ionic radius the measurements of $D_{\text {metal }}$ and $D_{\mathrm{H}_{2} \mathrm{O}}$ of the same sample were performed. The viscosity of the solution was estimated from the solvent $D_{\mathrm{H}_{2} \mathrm{O}}$ as $\eta=\frac{1}{673 \times 10^{-12}} \frac{k T}{\pi D}$ following to the SE relation (experimental value of $c r_{\mathrm{s}}$ of pure $\mathrm{H}_{2} \mathrm{O}$ is $673 \mathrm{pm}$ ). Then the dynamic ionic radius $r_{\mathrm{s}}$ of an alkali metal was evaluated from the $D$ of an alkali metal as $r_{\mathrm{s}}=\frac{1}{4.8 D} \frac{k T}{\pi \eta}$, where $c$ is assumed 4.8 .

The diffusion constants of $\mathrm{Li}^{+}, \mathrm{Na}^{+}, \mathrm{Cs}^{+}$were reported in $\mathrm{D}_{2} \mathrm{O}$ at $298 \mathrm{~K}$ for $1 \mathrm{M}$ concentration to be $0.92,1.2$, and $1.8 \times 10^{-9} \mathrm{~m}^{2}$ $\mathrm{s}^{-1}$, respectively. ${ }^{13}$ Our values are consistent to the reported data, and the trend that the increase of the $D$ values as the increase of the alkali metal size is quite consistent with each other.

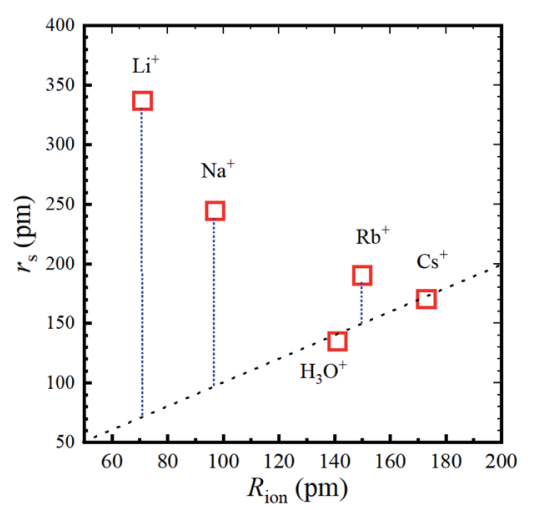

Fig. 5 Stokes radius (i.e., dynamic ionic radius) of the alkali metal ions versus the ionic radius $\left(R_{\text {ion }}\right)$ at $303 \mathrm{~K}$. The dotted line is a guide for the $1: 1$ relation. 
Table 2 Experimental values of $D_{\text {alkali }}$ and $D_{\mathrm{H}_{2} \mathrm{O}}$ in diluted region at $303 \mathrm{~K}$ and estimated viscosity, dynamic ionic radius $r_{\mathrm{s}}$, and radial hydration number

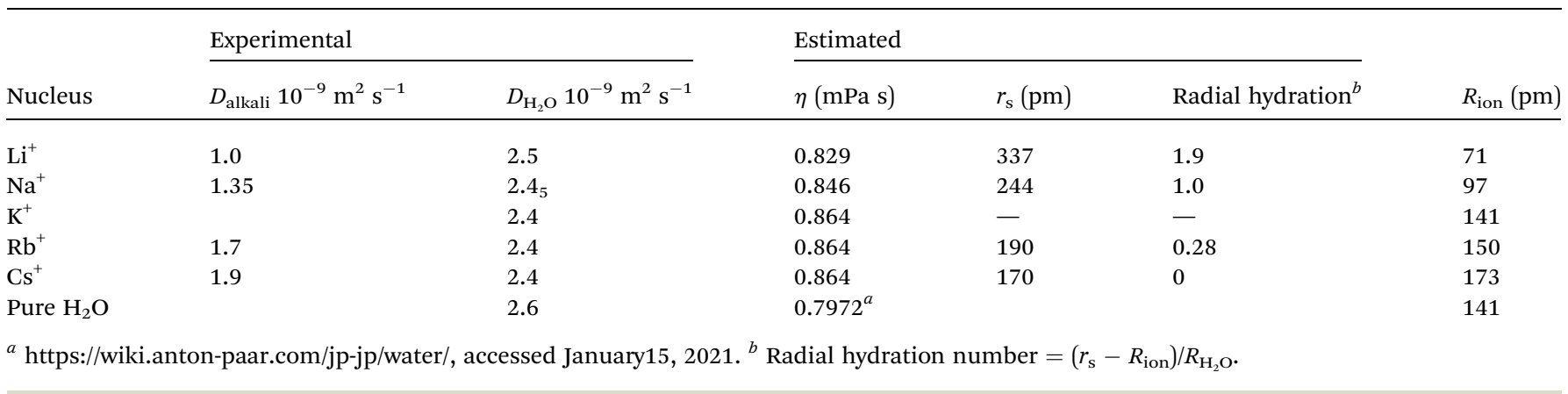

The $r_{\mathrm{s}}$ values were obtained experimentally on timescale of $10^{-6} \mathrm{~s}$ which is much longer than the commonly used timescale for spectroscopy and MO calculations. This means that PFGNMR experiments can provide important information for electrochemistry in the similar timescale of ionic conductivity and viscosity.

The calculated $r_{\mathrm{s}}$ values are plotted versus $R_{\mathrm{ion}}$ in Fig. 5 and the numerical values are given in Table 2.

For a better understanding the relations between the dynamic and static ionic radii, Fig. 6 illustrates the relations between $r_{\mathrm{s}}$ and $R_{\text {ion }}$.

As is well known, the larger the atomic number of alkali metal, the larger the $R_{\text {ion }}$. Experimental results on the dynamic ionic radius show an opposite trend; a reduction in the Stokes radius $r_{\mathrm{s}}$ with increasing alkali atomic number. The dynamic radius of $\mathrm{Li}$ ion was the largest compared with the static ionic radius. To interpret this tendency, it is assumed that the dynamic ionic radius is induced by hydration and the hydrated alkali ions diffuse accompanied by $\mathrm{H}_{2} \mathrm{O}$ molecules. A simple calculation was performed to estimate the number of $\mathrm{H}_{2} \mathrm{O}$ molecules in the radial direction (the hydration number) as $\left(r_{\mathrm{s}}\right.$ $\left.-R_{\text {ion }}\right) / R_{\mathrm{H}_{2} \mathrm{O}}$ for each alkali metal ion (Table 2 ). The hydration number of $\mathrm{Li}^{+}$is about 2 in the radial direction, and larger alkali metal ions are less hydrated. Then the hydration number is plotted versus hydration enthalpy and ionization energy reported ${ }^{18}$ in Fig. 7(a) and (b), respectively.

The hydration numbers of the alkali metal ions determined by the PFG NMR method correlate well with the hydration enthalpy. The relationship between hydration enthalpy and ionization energy for numerous ions have been discussed widely, ${ }^{18}$ and in this paper, the plot of the hydration number versus ionization energy for the alkali metal ions suggests that the hydration of $\mathrm{Li}^{+}$is very large.

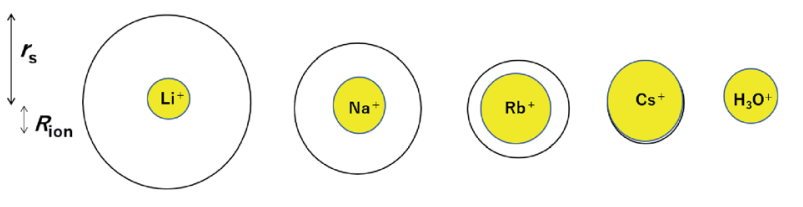

Fig. 6 Relations between the dynamic ionic radius $\left(r_{\mathrm{s}}\right)$ and static ionic radius $\left(R_{\text {ion }}\right)$ for the alkali metal ions in aqueous solutions.

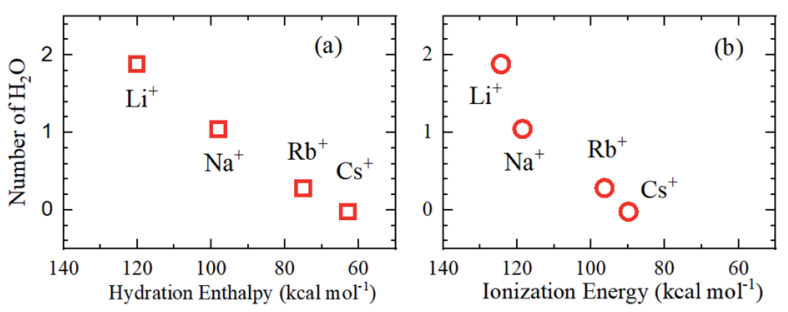

Fig. $7 \quad \mathrm{H}_{2} \mathrm{O}$ number in the radial direction versus (a) hydration enthalpy and (b) ionization energy.

\section{Conclusions}

The diffusion constants of the NMR-active nuclei of alkali metal ions have been determined by the PFG NMR method on a timescale of $10^{-3} \mathrm{~s}$ in a space of $10^{-6} \mathrm{~m}$. The initial position of the NMR-active nucleus is marked by the first PFG and after time interval $\Delta\left(10^{-3} \mathrm{~s}\right.$ order $)$, the migrated position is detected by the second PFG. The dynamic ion radius (i.e., the Stokes radius) of each alkali metal ion was determined. The hydrated sphere diffuses together with the alkali metal ion. The hydration sphere is largest for $\mathrm{Li}^{+}$, followed by $\mathrm{Na}^{+}, \mathrm{Rb}^{+}$, and $\mathrm{Cs}^{+}$, and $\mathrm{Cs}^{+}$has almost no hydration sphere. During the diffusion period, the PFG NMR method does not provide any information on the $\mathrm{H}_{2} \mathrm{O}$ exchange between the hydration sphere and the bulk.

In this study, the theoretically derived SE relation was experimentally proved for the first time in the case of alkali metal ions in aqueous solution. The experimental value of the constant, $c=4.8$ for pure $\mathrm{H}_{2} \mathrm{O}$ is reasonable in the aqueous solutions.

\section{Conflicts of interest}

There are no conflicts to declare.

\section{References}

1 H. Ohtaki and T. Radnai, Chem. Rev., 1993, 93, 1157-1204, DOI: $10.1021 /$ cr00019a014. 
2 Y. Marcus, Chem. Rev., 1988, 88, 1475-1498, DOI: 10.1021/ cr00090a003.

3 R. Mancinelli, A. Botti, F. Bruni, M. A. Ricci and A. K. Soper, J. Phys. Chem. B, 2007, 111, 13570-13577, DOI: 10.1021/ jp075913v.

4 M. Nagasaka, H. Yuzawa and N. Kosugi, J. Phys. Chem. B, 2017, 121, 10957-10964, DOI: 10.1021/acs.jpcb.7b09789.

5 J. Mähler and I. Persson, Inorg. Chem., 2012, 51, 425-438, DOI: $10.1021 /$ ic2018693.

6 S. Roy and V. S. Bryantsev, J. Phys. Chem. B, 2018, 122, 1206712076, DOI: 10.1021/acs.jpcb.8b08414.

7 I. M. Zeron, J. L. F. Abascal and C. Vega, J. Chem. Phys., 2019, 151, 134504, DOI: 10.1063/1.5121392.

8 X. Wang, D. Toroz, S. Kim, S. L. Clegg, G.-S. Park and D. D. Tommaso, Phys. Chem. Chem. Phys., 2020, 22, 1630116313, DOI: 10.1039/d0cp01957g.

9 H. J. V. Tyrell and K. R. Harris, Diffusion in Liquids: A Theoretical and Experimental Study, ButterworthHeinemann, London, 1984.

10 K. Hayamizu, Electrochim. Acta, 2017, 254, 101-111, DOI: 10.1016/j.electacta.2017.09.051, and citations therein.
11 K. Hayamizu, S. Tsuzuki, S. Seki, K. Fujii, M. Suenaga and Y. Umebayashi, J. Chem. Phys., 2010, 133, 194505, DOI: 10.1063/1.3505307.

12 K. Hayamizu, S. Tsuzuki, S. Seki and Y. Umebayashi, J. Chem. Phys., 2011, 135, 084505, DOI: 10.1063/1.3625923.

13 B. M. Braun and H. Weingärtner, J. Phys. Chem., 1988, 92, 1342-1346, DOI: 10.1021/j100316a065.

14 V. I. Volkov, A. V. Chernyak, D. V. Golubenko, V. A. Tverskoy, G. A. Lochin, E. S. Odjigaeva and A. B. Yaroslavtsev, Membranes, 2020, 10, 272, DOI: 10.3390/ membranes10100272.

15 M. Holz, S. R. Heil and A. Sacco, Phys. Chem. Chem. Phys., 2000, 2, 4740-4742, DOI: 10.1039/b005319h.

16 Y. Aihara, K. Sugimoto, W. S. Price and K. Hayamizu, J. Chem. Phys., 2000, 113, 1981-1991, DOI: 10.1063/1.482004.

17 K. Hayamizu, Y. Aihara, S. Arai and C. Garcia-Martinez, J. Phys. Chem. B, 1999, 103, 519-524, DOI: 10.1021/jp9825664.

18 J. E. House Jr, L. A. Reif Jr and J. D. House, Thermochim. Acta, 1983, 66, 365-368, DOI: 10.1016/0040-6031(93)85050-J. 